\title{
Supplement
}

\section{Chemical preparation}

5 mM Ferrozine-acetate reagent was made by a mixture of $246.2 \mathrm{mg}$ ferrozine dissolved in $50 \mathrm{~mL}$ DI water and $19.27 \mathrm{~g}$ ammonium acetate dissolved in $50 \mathrm{~mL}$ DI water.

$5 \quad 2.8$ mM Bathocuproine was prepared by dissolving $504.6 \mathrm{mg}$ bathocuproine in $500 \mathrm{~mL}$ DI water.

1.6 M Hydroxylamine hydrochloride was prepared by dissolving $50 \mathrm{~g}$ hydroxylamine hydrochloride in $450 \mathrm{~mL}$ DI water.

1 M Sodium citrate was prepared by dissolving $147.05 \mathrm{~g}$ sodium citrate dihydrate in $500 \mathrm{~mL}$ DI water.

5 M Sodium hydroxide was prepared by dissolving $20 \mathrm{~g}$ sodium hydroxide in $100 \mathrm{~mL}$ DI water.

\section{Conversion of mass in Da to size in $\mathbf{n m}$}

10 The Dalton (or unified atomic mass unit, Da) is a unit of mass, defined as 1/12 of the mass of an unbound neutral atom of carbon-12 in its nuclear and electronic ground state and at rest (Taylor, 2009). The mass of one mole of a substance, measured in grams, is numerically equal to the average mass of one of its constituent particles, measured in daltons. Therefore,

$$
1 g=6.023 \times 10^{23} \mathrm{Da},
$$

15 where $6.023 \times 10^{23}$ is Avagadro's Number.

There are several assumptions when calculating the conversion of mass in Da to size in $\mathrm{nm}$. We assume that all the watersoluble species in $\mathrm{PM}_{2.5}$ have approximately the same density of $1.4 \mathrm{~g} \mathrm{~cm}^{-3}$. The volume occupied by a spherical particle of mass $\mathrm{M}$ in Dalton is:

$$
V\left(\mathrm{~nm}^{3}\right)=\frac{M(\text { mass })}{\rho(\text { density })}=\frac{10^{21} \mathrm{~nm}^{3} / \mathrm{cm}^{3}}{1.4 \mathrm{~g} / \mathrm{cm}^{3} \times 6.023 \times 10^{23} \mathrm{Da} / \mathrm{g}} \times M(\mathrm{Da})=1.186 \times 10^{-3}\left(\frac{\mathrm{nm}^{3}}{\mathrm{Da}}\right) \times M(\mathrm{Da}),
$$

20 where $10^{21}$ is a unit conversion factor, 1.4 is the assumed particle density, and M (Da) is the particle mass in Daltons. Then assuming all the particles have the same simplest shape of a sphere. the volume of this sphere can be expressed as

$$
V=\frac{4}{3} \pi\left(\frac{D_{p}}{2}\right)^{3}
$$

Therefore, the diameter of the particle can be estimated by:

$$
D_{p}(n m)=2 \times(3 V / 4 \pi)^{1 / 3}=0.131 M^{1 / 3} .
$$

25 In this case, when $M=3 \mathrm{kDa}, D_{p}=1.89 \mathrm{~nm}$; when $M=30 \mathrm{kDa}, D_{p}=4.08 \mathrm{~nm}$ (Erickson, 2009). 
Note that not all particles have a uniform density of $1.4 \mathrm{~g} \mathrm{~cm}^{-3}$, this approximation and simplification may cause uncertainty in the calculation of the particle size. In addition, the particle shape is not always an ideal sphere. This "spherical particle" assumption will lead to underestimation of particle diameter.

\section{Effects of membrane rejection}

30 Membranes fabricated that have set average pore size were used for ultrafiltration permeation in this study. Nevertheless, these membranes can cause problems during ultrafiltration permeation and may lead to underestimation of particle concentration (passing through the membranes). For example, some colloidal?? materials may be rejected by the membranes due to charge repulsion. Additionally, high-concentration samples may cause accumulation of materials on the membranes, leading to rejection of smaller sized molecules and ultimately underestimation of the concentration. According to the

35 permeation coefficient model, the actual filtrate concentration $\left(c_{f}\right)$ could be expressed as

$$
c_{f}=c_{r, 0} \frac{1-F^{P_{c}}}{1-F}
$$

where $c_{r, 0}$ is the concentration of materials able to pass through the membrane. $\mathrm{F}$ is the fraction of the total filtrate volume remaining before the membrane. $P_{c}$ refers to the permeation coefficient. In this study, to make the measured concentration $c_{r, 0}$ as close as possible to the actual filtrate concentration, excessive centrifugation time was applied and $\mathrm{F}$ was close to 0 .

40 Therefore, the effects of membrane rejection in our study is expected to be small.

\section{Effect of dilution ratio on soluble fraction of metal}

What is considered water-soluble metal may be affected by the degree of dilution of the sample in the extraction process. Following methods developed for characterizing water-soluble organic carbon (Psichoudaki and Pandis, 2013), the effect of dilution ratio on the soluble fraction of metal $(f)$ can be expressed with the variable $P\left(\mathrm{~cm}^{3} \mathrm{~m}^{-3}\right)$, which is the ratio of the

45 volume of extract water $\left(V_{w}(m L)\right)$ per volume of ambient air that passed through the portion of the filter $\left(V_{a}\left(m^{3}\right)\right)$ that was analyzed. $P$ is $\sim 0.5$ in this study.

Assume that the dissolution of a single compound is not affected by the presence of the other components. The mass of a Feor $\mathrm{Cu}$-contained compound $\mathrm{A}$ that can be dissolved during the extraction (assuming the system reaches equilibrium) is equal to $V_{w} \cdot S_{A}$, where $S_{A}\left(\mathrm{ng} \mathrm{mL} \mathrm{m}^{-1}\right)$ is the saturated solubility of metal A. The total mass of A is equal to $V_{A} \cdot C_{A}$, where $C_{A}\left(\mathrm{ng} \mathrm{m}^{-3}\right)$

50 is the ambient concentration of metal $\mathrm{A}$. Now the fraction of $\mathrm{A}$ in the aqueous phase is given by

$$
f_{A}=\frac{V_{w} \cdot S_{A}}{V_{A} \cdot C_{A}}=\frac{P \cdot S_{A}}{C_{A}} .
$$

This model predicts that the water-soluble fraction of $\mathrm{A}$ is proportional to the $\mathrm{P}$ parameter. As predicted by this model, Figure S8 shows the water-soluble fraction of a compound as a function of its solubility, for different ambient concentrations 
when $\mathrm{P}=0.5 \mathrm{~cm}^{3} \mathrm{~m}^{-3}$. According to Fig. $\mathrm{S} 8$, Fe- or Cu-contained compound with solubility higher than $10^{-3} \mathrm{~g} \mathrm{~L}^{-1}$ always

55 contribute all of their mass to the water-soluble fraction of $\mathrm{Fe}$ or $\mathrm{Cu}$, regardless of their ambient concentration, while species with solubility less than $10^{-6} \mathrm{~g} \mathrm{~L}^{-1}$ do not contribute significantly. Slight change in $\mathrm{P}$ can affect the soluble fraction of components with solubility within $10^{-6}$ to $10^{-3} \mathrm{~g} \mathrm{~L}^{-1}$. The solubilities of most soluble Fe and $\mathrm{Cu}$ components are much higher than $10^{-3} \mathrm{~g} \mathrm{~L}^{-1}$ (e.g. $\mathrm{Fe}(\mathrm{II}) \mathrm{SO}_{4}$ ), which could be fully dissolved even if $\mathrm{P}$-value decreases to 0.01 . Thus, the value of $\mathrm{P}=0.5$ $\mathrm{cm}^{3} \mathrm{~m}^{-3}$ is acceptable in this study for extracting most soluble $\mathrm{Fe}$ and $\mathrm{Cu}$ species in the ambient aerosol. Note that there is no

60 unified P-value for the extraction of WS metals and the level of WS metals in different aerosol samples varies greatly. WS metal measurements under high concentration might tend to give low values unless higher $\mathrm{P}$ values are used. 


\section{Tables \& Figures}

Table S1: Statistical summary of transition metal concentrations in $\mathrm{PM}_{2.5}$ measured in Atlanta in $2017(\mathrm{~N}=355)$ based on ICP-MS measurement.

\begin{tabular}{ccccccc}
\hline & Total Fe & Total $\mathrm{Cu}$ & Total Mn & WS Fe & WS Cu & WS Mn \\
\hline Mean $\left(\mathrm{ng} \mathrm{m}^{-3}\right)$ & 203.7 & 30.7 & 4.0 & 19.5 & 15.2 & 2.0 \\
Median $\left(\mathrm{ng} \mathrm{m}^{-3}\right)$ & 156.3 & 26.0 & 3.44 & 11.9 & 11.7 & 1.8 \\
Maximum $\left(\mathrm{ng} \mathrm{m}^{-3}\right)$ & 1643.4 & 204.5 & 19.3 & 123.7 & 141.5 & 6.4 \\
Minimum $\left(\mathrm{ng} \mathrm{m}^{-3}\right)$ & $<$ LOD & $<$ LOD & $<$ LOD & $<$ LOD & $<$ LOD & $<$ LOD \\
RSD & 0.90 & 0.68 & 0.72 & 1.11 & 0.83 & 0.57
\end{tabular}

65

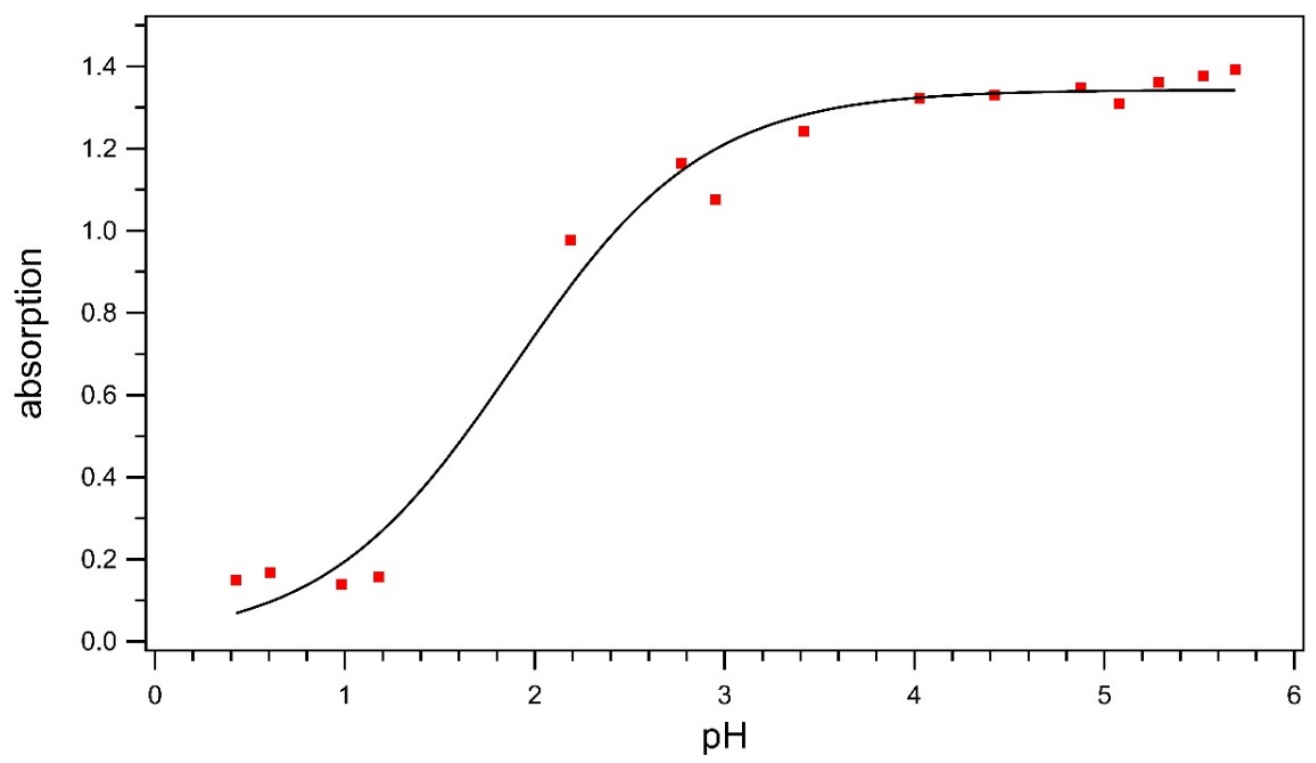

Figure S1: Effect of $\mathrm{pH}$ on the formation of $\mathrm{Cu}(\mathrm{I})$ complex of bathocuproine. The y-axis represents the light absorption at $484 \mathrm{~nm}$. 
(a)

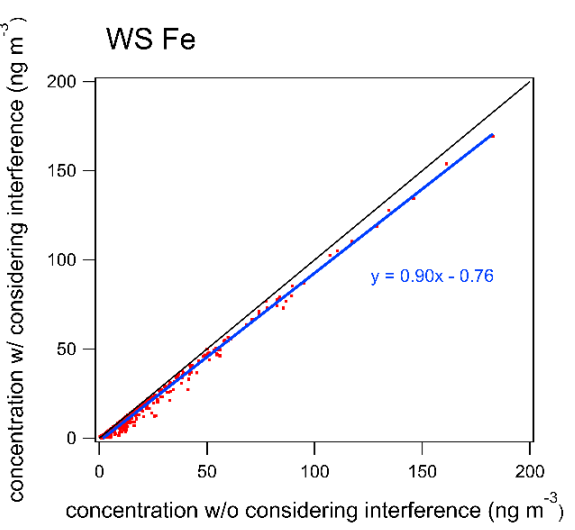

(c)

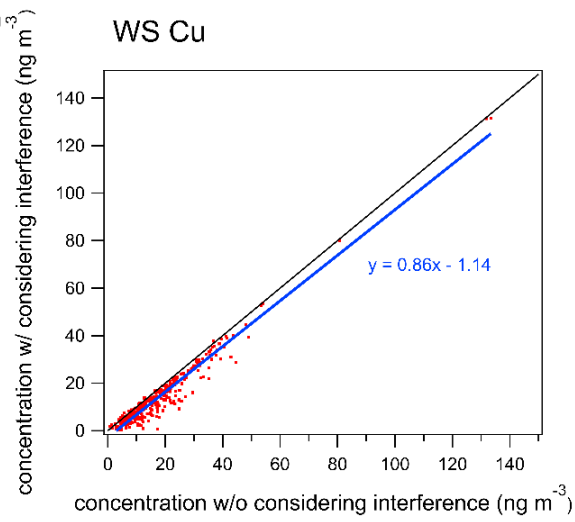

(b) ?

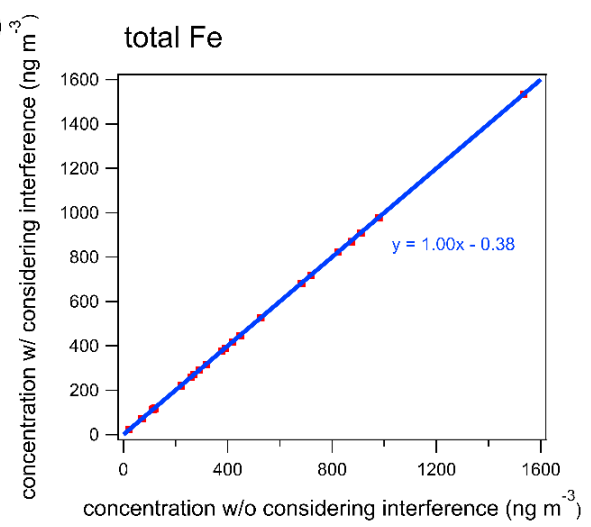

(d) ?

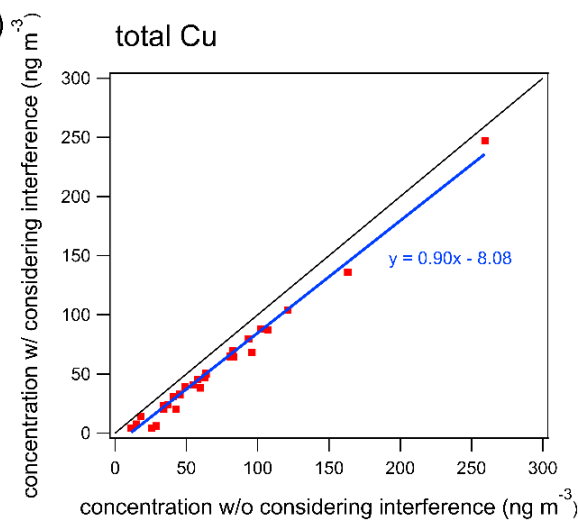

(e) ${ }_{\varepsilon}^{-}$FireX-AQ WS Cu

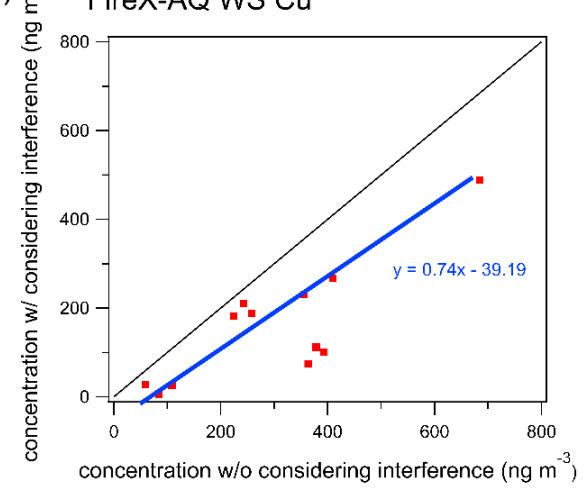

Figure S2: Influence of light absorption of other species in the sample on the determination of (a) WS Fe, (b) total Fe, (c) WS $\mathrm{Cu},(\mathrm{d})$ total $\mathrm{Cu}$ for data collected in Atlanta. Plot (e) shows an extreme example (FireX-AQ) involving the sampling of 85 wildfire smoke, which has high concentrations of $\mathrm{BC}$ and $\mathrm{BrC}$ and low levels of $\mathrm{Fe}$ and $\mathrm{Cu}$. York regressions are shown and the predicted intercept is interpreted as the average systematic offset caused by the interference of other light-absorbing species. 


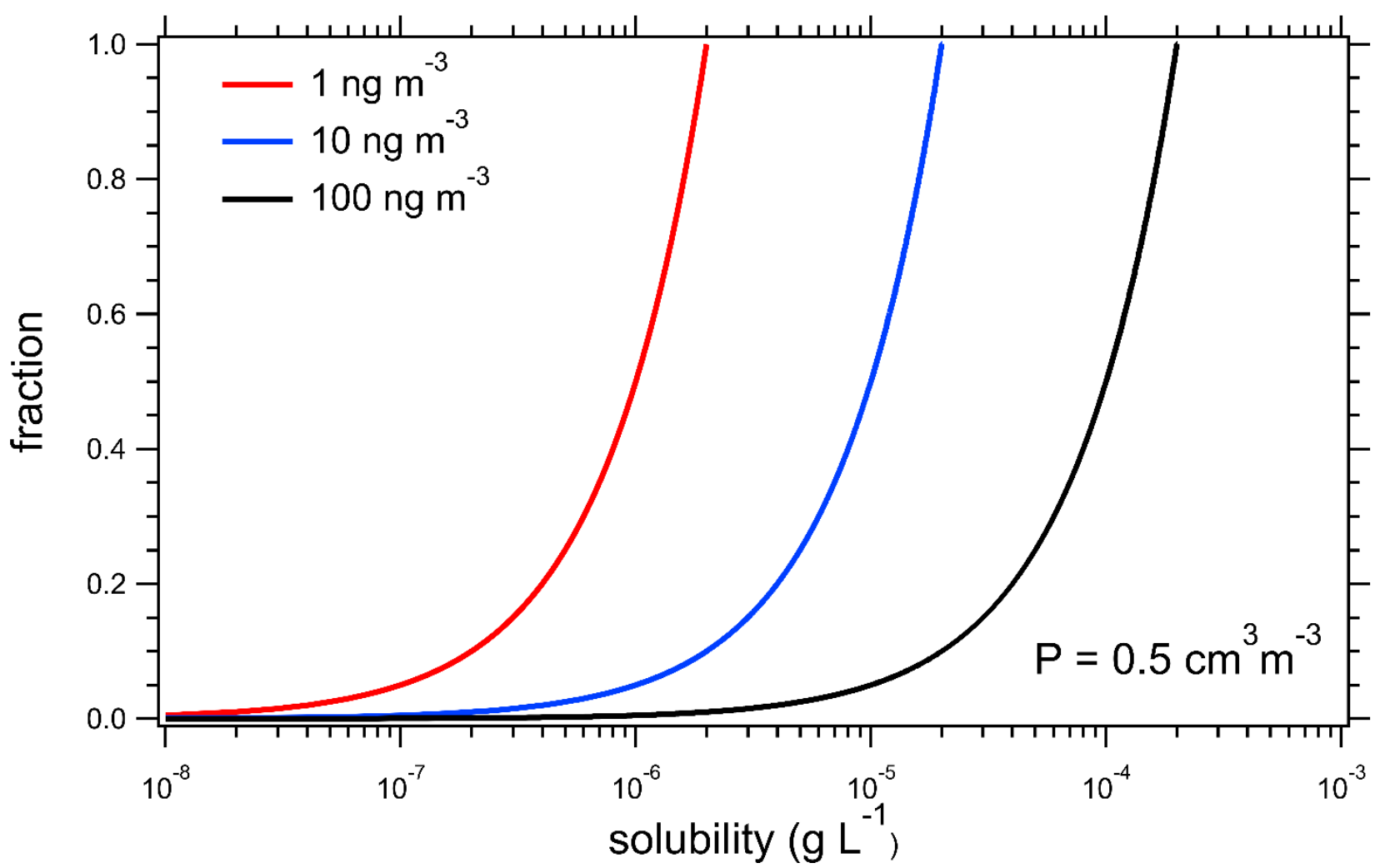

Figure S3. Water-soluble fraction of a compound as a function of its solubility and ambient concentration for $\mathrm{P}=0.5 \mathrm{~cm}^{3} \mathrm{~m}^{-}$ 


\section{References}

Erickson, H. P.: Size and shape of protein molecules at the nanometer level determined by sedimentation, gel filtration, and electron microscopy, Biological procedures online, 11, 32, 2009.

Psichoudaki, M. and Pandis, S. N.: Atmospheric aerosol water-soluble organic carbon measurement: a theoretical analysis, Environmental science \& technology, 47, 9791-9798, 2013.

105 Taylor, B. N.: Molar mass and related quantities in the New SI, Metrologia, 46, L16, 2009. 